\title{
Pharmacokinetic, Pharmacodynamic, and Drug-Interaction Profile of Remdesivir, a SARS-CoV-2 Replication Inhibitor
}

\author{
Rita Humeniuk ${ }^{1}$ - Anita Mathias ${ }^{1} \cdot$ Brian J. Kirby $^{1} \cdot$ Justin D. Lutz ${ }^{1} \cdot$ Huyen Cao ${ }^{1} \cdot$ Anu Osinusi $^{1} \cdot$ Darius Babusis $^{1}$. \\ Danielle Porter ${ }^{1} \cdot$ Xuelian Wei $^{1} \cdot$ John Ling $^{1} \cdot$ Y. Sunila Reddy ${ }^{1} \cdot$ Polina German ${ }^{1}$
}

Accepted: 7 January 2021 / Published online: 30 March 2021

(c) The Author(s) 2021

\begin{abstract}
Remdesivir (RDV, Veklury ${ }^{\circledR}$ ) is a once-daily, nucleoside ribonucleic acid polymerase inhibitor of severe acute respiratory syndrome coronavirus 2 replication. Remdesivir has been granted approvals in several countries for use in adults and children hospitalized with severe coronavirus disease 2019 (COVID-19). Inside the cell, remdesivir undergoes metabolic activation to form the intracellular active triphosphate metabolite, GS-443902 (detected in peripheral blood mononuclear cells), and ultimately, the renally eliminated plasma metabolite GS-441524. This review discusses the pre-clinical pharmacology of RDV, clinical pharmacokinetics, pharmacodynamics/concentration-QT analysis, rationale for dose selection for treatment of patients with COVID-19, and drug-drug interaction potential based on available in vitro and clinical data in healthy volunteers. Following single-dose intravenous administration over $2 \mathrm{~h}$ of an RDV solution formulation across the dose range of 3-225 mg in healthy participants, RDV and its metabolites (GS-704277and GS-441524) exhibit linear pharmacokinetics. Following multiple doses of RDV $150 \mathrm{mg}$ once daily for 7 or 14 days, major metabolite GS-441524 accumulates approximately 1.9-fold in plasma. Based on pharmacokinetic bridging from animal data and available human data in healthy volunteers, the RDV clinical dose regimen of a 200-mg loading dose on day 1 followed by 100-mg maintenance doses for 4 or 9 days was selected for further evaluation of pharmacokinetics and safety. Results showed high intracellular concentrations of GS-443902 suggestive of efficient conversion from RDV into the triphosphate form, and further supporting this clinical dosing regimen for the treatment of COVID-19. Mathematical drug-drug interaction liability predictions, based on in vitro and phase I data, suggest RDV has low potential for drug-drug interactions, as the impact of inducers or inhibitors on RDV disposition is minimized by the parenteral route of administration and extensive extraction. Using physiologically based pharmacokinetic modeling, RDV is not predicted to be a clinically significant inhibitor of drug-metabolizing enzymes or transporters in patients infected with COVID-19 at therapeutic RDV doses.
\end{abstract}

Rita Humeniuk

\section{Key Points}

Remdesivir has low predicted drug-drug interaction potential based on in vitro data, human phase I studies in healthy volunteers, and physiologically based pharmacokinetic modeling.

A clinical dosing regimen for the treatment of coronavirus disease 2019, a 200-mg loading dose followed by 100 -mg maintenance doses for a total duration of 5 or 10 days, showed consistent pharmacokinetics with previous studies and was generally well tolerated in healthy volunteers.

Rita.Humeniuk@gilead.com

1 Gilead Sciences, Inc., 333 Lakeside Drive, Foster City, CA 94404, USA 


\section{Introduction}

The coronavirus disease 2019 (COVID-19) pandemic, caused by severe acute respiratory syndrome coronavirus 2 (SARS-CoV-2), has spread globally causing significant morbidity and mortality $[2,3]$. The most common symptoms include fever, dry cough, dyspnea, chest pain, fatigue, and myalgia [4-6]. Severity of illness can vary from mild to critical and the risk factors for severe illness include older age ( $\geq 65$ years) and comorbidities such as diabetes mellitus, heart disease, lung disease, hypertension, and obesity [7]. In the USA, the current (as of December 2020) clinical management for COVID-19 cases that require hospitalization includes supportive care, corticosteroids (dexamethasone), antiviral therapy (remdesivir [RDV]), and immune-based therapies [8]. For COVID-19 cases not requiring hospitalization, the FDA has recently issued an Emergency Use Authorization for two investigational monoclonal antibody therapies, bamlanivimab (LYCoV555) and casirivimab plus imdevimab, for the treatment of non-hospitalized patients who are either at high risk of progressing to severe COVID-19 and/or hospitalization or mild-to-moderate disease, respectively $[9,10]$.

Remdesivir (Veklury ${ }^{\circledR}$ ) is an adenosine-analog nucleotide prodrug that undergoes metabolic activation to form the intracellular active triphosphate, GS-443902, that inhibits viral RNA polymerases [11]. Remdesivir has broad-spectrum in vitro antiviral activity against members of the filoviruses (including Ebola virus and Marburg virus), and other RNA viruses such as paramyxoviruses (respiratory syncytial virus, Nipah virus, and Hendra virus) and coronaviruses [CoV] (Middle East respiratory syndrome [MERS] CoV and SARS CoV) [12-14]. In vitro and in vivo, RDV has shown potent antiviral activity against SARS-CoV-2 [15-17]. Remdesivir is approved or authorized for temporary use in approximately 50 countries worldwide. Remdesivir was approved in adults and pediatric patients 12 years of age and older weighing at least $40 \mathrm{~kg}$ in the European Economic Area (3 July, 2020), Canada (27 July, 2020), and the USA (22 October, 2020) [18-20]. In the USA, the FDA approved remdesivir for use in adult and pediatric patients 12 years of age and older and weighing at least $40 \mathrm{~kg}$ (about 88 pounds) for the treatment of COVID-19 requiring hospitalization. On the same date, 22 October, 2020, the FDA revised the Emergency Use Authorization for remdesivir, originally issued on 1 May, 2020, to authorize the drug's use for the treatment of suspected or laboratory-confirmed COVID-19 in hospitalized pediatric patients weighing $3.5 \mathrm{~kg}$ to less than $40 \mathrm{~kg}$ or hospitalized pediatric patients less than 12 years of age weighing at least $3.5 \mathrm{~kg}$ [21]. This review summarizes the clinical and pre-clinical pharmacology of RDV with a focus on clinical pharmacokinetics (PK), pharmacodynamics/concentration-QT (C-QT) analysis, rationale for dose selection for clinical studies in patients with COVID-19, and drug interaction potential.

\section{Pre-Clinical Pharmacology}

\subsection{Chemical and Physical Properties}

Remdesivir [chemical name: 2-ethylbutyl N-\{(S)-[2-C(4aminopyrrolo[2, 1-f] $[1,2,4]$ triazin-7-yl)-2-5-anhydro-daltrononitril-6- $O$-yl]phenoxyphosphoryl $\}$-L-alaninate] is a low-molecular-weight $(602.6 \mathrm{~g} / \mathrm{mol})$ prodrug with the molecular formula $\mathrm{C} 27 \mathrm{H} 35 \mathrm{~N} 6 \mathrm{O} 8 \mathrm{P}$ and a chemical structure as shown in Fig. 1. Remdesivir is administered by intravenous (IV) infusion [11].

Remdesivir was developed for IV administration because of poor hepatic stability (extensive first-pass extraction). This compound is available as both a solution and a lyophilized injection formulation. The liquid formulation provides a ready-to-use dosage form that does not require reconstitution prior to administration; thereby, simplifying the preparation at the administration site. The lyophilized formulation exhibits improved physiochemical stability, and enables a longer shelf life and stability at room temperature, which may be advantageous in resource-limited settings [1].

\subsection{Pharmacodynamic Properties}

\subsubsection{RDV Intracellular Metabolic Pathway}

Remdesivir undergoes intracellular activation to form GS-443902 (an analog of adenosine triphosphate) that selectively inhibits viral RNA polymerases and has broadspectrum activity against members of the $\operatorname{CoV}[15,16]$. The intracellular activation process involves hydrolase cleavage of RDV by carboxylesterases to form an intermediate metabolite, GS-704277. Subsequently, cleavage of the phosphoramidate bond results in the formation of the nucleoside analog monophosphate, GS-441524-MP, which

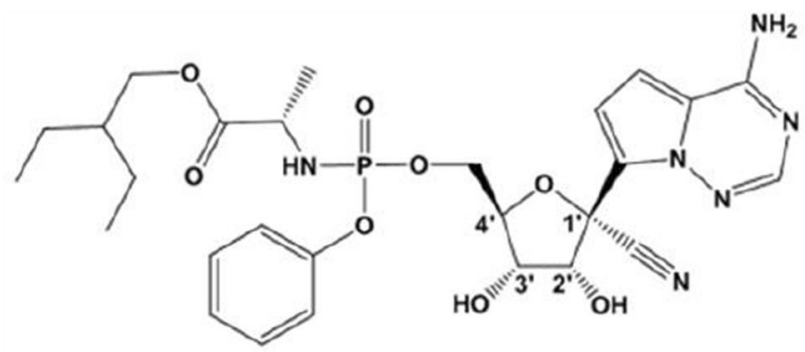

Fig. 1 Remdesivir chemical structure 
is further phosphorylated to the pharmacologically active nucleoside triphosphate, GS-443902 [1]. Dephosphorylation of GS-441524-MP results in the formation of the nucleoside analog, GS-441524, that itself is not as efficiently re-phosphorylated. The intracellular metabolic pathway of RDV is presented in Fig. 2. Remdesivir and its metabolites (GS704277 and GS-441524) are detectable in plasma, whereas the active triphosphate GS-443902 is only detected intracellularly, with peripheral blood mononuclear cells (PBMCs) used as a clinical surrogate cell type for assessing activation to the active triphosphate GS-443902.

\subsubsection{RDV Antiviral Activity}

Remdesivir has demonstrated potent in vitro activity against SARS-CoV-2 in multiple relevant cells types as well as in vivo activity in animal models of SARS-CoV-2 infection. In vitro, RDV exhibited antiviral activity against a clinical isolate of SARS-CoV-2 in primary human airway<smiles>CCC(CC)COC(=O)[C@H](C)N[P@](=O)(OC[C@H]1O[C@](c2ccccc2)(c2ccc3c(N)ncnn23)[C@H](O)[C@@H]1O)Oc1cccs1</smiles><smiles>C[C@@H](NP(=O)([O-])OC[C@H]1O[C@@](C#N)(c2ccc3c(N)ncnn23)[C@H](O)[C@@H]1O)C(=O)O</smiles>

GS-704277

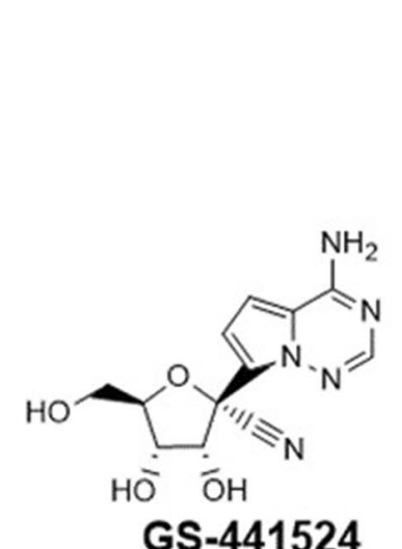

GS-441524

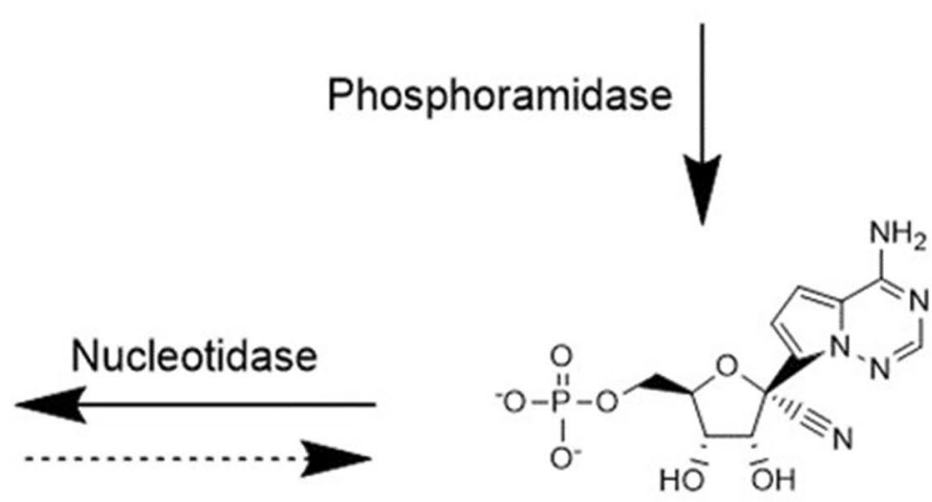

GS-441524-MP<smiles>N#C[C@]1(c2ccc3c(N)ncnn23)O[C@H](COP(=O)([O-])OP(=O)([O-])OP(=O)([O-])[O-])[C@@H](O)[C@H]1O</smiles>

Fig. 2 Intracellular metabolic pathway of remdesivir (GS-5734TM) 
epithelial cells with a half-maximal effective concentration of $9.9 \mathrm{nM}$ and also potently $(280 \mathrm{nM})$ inhibited SARSCoV-2 replication in Calu-3 human lung cells [22]. In biochemical assays assessing RDV-triphosphate incorporation by the SARS-CoV-2, SARS-CoV, and MERS-CoV viral RNA-dependent RNA polymerase complexes, RDV triphosphate was selectively incorporated over the natural nucleotide substrate adenosine triphosphate and inhibited viral RNA synthesis with a half-maximal inhibitory concentration value of $32 \mathrm{nM}$ for MERS-CoV [16].

In vivo, RDV showed therapeutic efficacy in SARS-CoV2-infected rhesus monkeys and prophylactic and therapeutic efficacy in MERS-CoV-infected rhesus monkeys [23, 24]. Briefly, $12 \mathrm{~h}$ after inoculation with SARS-CoV-2, rhesus monkeys received an RDV 10-mg/kg IV loading dose followed by maintenance doses of RDV $5 \mathrm{mg} / \mathrm{kg}$ at $24 \mathrm{~h}$ postinoculation and once daily thereafter for a total of 6 days of treatment. The aim of the loading dose was to rapidly generate high GS-443902 concentrations following the first dose. Treatment with this regimen resulted in a significant reduction in clinical signs of respiratory disease, lung pathology and gross lung lesions, and viral RNA levels compared with vehicle-treated animals [23].

In MERS-CoV-infected monkeys, prophylactic administration of RDV at $5 \mathrm{mg} / \mathrm{kg}$ once daily for 7 days using an IV bolus injection beginning 1 day prior to MERS-CoV inoculation resulted in a significant reduction in clinical scores, clinical signs of respiratory disease, and viral RNA levels compared with vehicle-treated animals. Therapeutic RDV treatment of $5 \mathrm{mg} / \mathrm{kg}$ once daily using an IV bolus injection was initiated $12 \mathrm{~h}$ post-inoculation (until 6 days post-inoculation) and also resulted in reduced clinical signs, reduced virus replication in the lungs, and decreased presence and severity of lung lesions (data on file) [15, 21]. Prophylactic RDV treatment resulted in significantly lower levels of MERS-CoV replication in the lungs with lung viral loads 2.5-4 logs lower in each lung lobe. The lung viral loads in therapeutic RDV-treated animals were lower when all lung lobes were combined owing to a large variation between animals compared to vehicle-treated animals [24]. Therapeutic RDV administration was also effective in mice infected with chimeric SARS-CoV encoding the SARS-CoV-2 RNAdependent RNA polymerase who showed decreased viral loads in the lungs and increased pulmonary function as compared to vehicle-treated animals [22].

\subsection{Preclinical PK}

In preclinical species, IV RDV is extensively metabolized by hydrolases, resulting in sequential appearance of the intermediate metabolite GS-704277 and nucleoside metabolite GS-441524 in plasma. Remdesivir showed broad tissue distribution and efficient activation to GS-443902 in both
PBMCs and respiratory tissues in monkeys. Following IV administration of $10 \mathrm{mg} / \mathrm{kg}\left[{ }^{14} \mathrm{C}\right] \mathrm{RDV}$ to Sprague-Dawley rats, most of the radioactivity was excreted within 48 $\mathrm{h}$ after administration. Means of $63.0 \%$ and $27.8 \%$ of the administered radioactivity in rats were excreted in urine and feces, respectively, by $168 \mathrm{~h}$ post-dose. In monkeys, means of $33.6 \%$ and $25.6 \%$ of the administered radioactivity were recovered in urine and feces, respectively, by $168 \mathrm{~h}$ postdose, indicating that renal and biliary excretion were the major routes of elimination of radioactivity in both species (data on file).

\section{Clinical Pharmacology}

\subsection{Absorption, Distribution, Metabolism and Elimination}

\subsubsection{Absorption}

The absolute bioavailability of both RDV formulations administered IV is $100 \%$. Following single IV dose of $\left[{ }^{14} \mathrm{C}\right]-\mathrm{RDV}(150 \mathrm{mg})$ infused over $30 \mathrm{~min}$ in healthy male participants, RDV was readily detectable in blood and plasma, reaching peak concentrations at the end of infusion. Remdesivir elimination (terminal elimination half-life $\left[t_{1 / 2}\right]$ approximately $1 \mathrm{~h}$ ) is followed by the sequential appearance of GS-704277, GS-441524 in plasma, and pharmacologically active metabolite, GS-443902 in PBMCs. Peak plasma concentrations of GS-704277 and GS-441524 were observed $0.75 \mathrm{~h}$ and $3.00 \mathrm{~h}$ post start of infusion, respectively (data on file). As RDV is administered as an IV formulation, its PK will not be altered by food.

\subsubsection{Distribution}

Remdesivir has moderate protein binding (approximately 88-93.6\% bound) in human plasma [11]. Protein binding in plasma is low for GS-704277 and GS-441524 (1-2\% bound). Remdesivir and GS-704277 were predominantly distributed to plasma relative to the cellular components of blood with mean whole blood/plasma concentration ratios of 0.76 and 0.56 , respectively [11]. GS-441524 showed some association with the cellular fraction with respective mean blood/ plasma ratios of 1.19 for human [11]. After a single IV dose of $\left[{ }^{14} \mathrm{C}\right]-\mathrm{RDV}$ in healthy male participants, the blood-toplasma ratio of $\left[{ }^{14} \mathrm{C}\right]$-radioactivity was 0.68 at $15 \mathrm{~min}$ from the start of infusion, increased over time reaching a ratio of 1.0 at $5 \mathrm{~h}$, indicating differential distribution of RDV and its metabolites to plasma or cellular components of blood (data on file). 


\subsubsection{Metabolism and Elimination}

The metabolism and elimination pathways for RDV were characterized in vitro and in human mass balance studies. The results of nonclinical evaluations suggested that RDV is primarily metabolized ( $80 \%$ of total metabolism) in the liver by carboxylesterase 1 , with cathepsin $\mathrm{A}$, and cytochrome P450 (CYP) 3A, contributing to 10\% each [11]. The results from the human mass balance study demonstrated that RDV is extensively metabolized and primarily eliminated in urine as the nucleoside metabolite GS-441524. Following administration of a single $150-\mathrm{mg}\left[{ }^{14} \mathrm{C}\right]-\mathrm{RDV}(100 \mu \mathrm{Ci})$ dose to healthy male participants, mean total recovery of the radioactive dose was $>92 \%$, consisting of approximately $74 \%$ and $18 \%$ recovered in urine and feces, respectively. Most of the dose recovered in the urine was as GS-441524 (48.6\%), confirming that renal clearance $\left(\mathrm{CL}_{\mathrm{r}}\right)$ was a major pathway for elimination of this metabolite; $10.3 \%$ of the dose was recovered in urine as RDV (unchanged) [11]. Mean total clearance and $\mathrm{CL}_{\mathrm{r}}$ values for RDV were $1171 \mathrm{~mL} / \mathrm{min}$ and $129 \mathrm{~mL} / \mathrm{min}$, respectively, indicating that most of its elimination occurred via the nonrenal route. Renal clearance for GS-441524 and GS-704277 were estimated as $151 \mathrm{~mL} / \mathrm{min}$ and $164 \mathrm{~mL} / \mathrm{min}$, respectively, suggesting a minor role of active secretion in the renal elimination of these metabolites. Considering the low protein binding of these metabolites ( $2 \%$ and $1 \%$ for GS-441524 and GS-704277, respectively), the estimated secretory clearance $\left(\mathrm{CL}_{\mathrm{r}}, \mathrm{s}\right)$ is $31 \mathrm{~mL} / \mathrm{min}$ ( $21 \%$ of $\left.\mathrm{CL}_{\mathrm{r}}\right)$ for GS-441524 and $44 \mathrm{~mL} / \mathrm{min}\left(27 \%\right.$ of $\left.\mathrm{CL}_{\mathrm{r}}\right)$ for GS-704277.

\subsection{Single- and Multiple-Dose PK and Dose Rationale for the Treatment of COVID-19}

\subsubsection{First-in-Human Studies}

Single and multiple escalating doses of RDV were investigated in two phase I first-in-human studies in heathy participants. Results for this study were described previously [1]. Briefly, following a single-dose IV solution formulation (3-225 mg dose range) administered over $2 \mathrm{~h}, \mathrm{RDV}$ and its metabolites exhibited dose-proportional PK. Both lyophilized and solution formulations of RDV provided comparable pharmacokinetic parameters. The effect of infusion duration on plasma RDV PK and metabolites was evaluated following single-dose IV administration of an RDV 75-mg lyophilized formulation over $30 \mathrm{~min}$. High concentrations of GS-443902 (220- to 370-fold above the in vitro half-maximal effective concentration against SARS-CoV-2 [9.9 nM)], the active triphosphate metabolite, were achieved following either a 2-h or a 30-min infusion, supporting recommendations of infusion times over 30-120 min in subsequent clinical studies. Following multiple doses (7-14 days) of
RDV $150 \mathrm{mg}$ once daily, metabolite GS-441524 accumulated approximately 1.9 -fold reaching steady state by day 4 , which is consistent with its $t_{1 / 2}$ of $\sim 24.5 \mathrm{~h}$. Overall, RDV exhibited favorable safety and pharmacokinetic profiles that supported once-daily dosing [1].

\subsubsection{Clinical Regimen Selection}

Selection of the RDV dosing regimen for the treatment of COVID-19 was based on the pharmacokinetic bridge from animal data to human doses and efficacy using (1) the results of in vivo efficacy studies conducted in SARS-CoV-2- and MERS-CoV-infected rhesus monkeys, (2) available pharmacokinetic data in healthy rhesus monkeys; and (3) pharmacokinetic and safety data from phase I single and multipledose first-in-human studies (Sect. 3.2.1) [1, 14, 23, 24].

Briefly, for the treatment of COVID-19, the approach was to target exposures (plasma and PBMCs) associated with efficacy observed following the 10/5 dosing regimen described in Sect. 2.2 in the infected rhesus monkeys. The clinical maintenance dose of RDV $100 \mathrm{mg}$ once daily was expected to provide systemic exposure of RDV in plasma and GS-443902 in PBMCs similar to those observed in rhesus monkeys at the $5-\mathrm{mg} / \mathrm{kg}$ IV dose of RDV (Table 1). Similarly, to the target efficacy seen at the $10-\mathrm{mg} / \mathrm{kg}$ loading dose in infected rhesus monkeys required a loading dose of $200 \mathrm{mg}$ in humans. This dose was projected to achieve similar exposure to the expected exposure in rhesus monkeys at $10 \mathrm{mg} / \mathrm{kg}$ (area under the concentration-time curve [AUC] 5

Table 1 Pharmacokinetics of remdesivir (RDV) in plasma and nucleoside triphosphate metabolite GS-443902 (peripheral blood mononuclear cells [PBMCs]) following repeat RDV doses (30-min intravenous infusion) to healthy rhesus monkeys $(5 \mathrm{mg} / \mathrm{kg})$ and healthy humans (100 mg)

\begin{tabular}{lll}
\hline PK parameter (mean $[\% \mathrm{CV}])$ & $\begin{array}{l}\text { Healthy rhesus } \\
\text { monkeys } \\
\text { RDV 5 mg/kg } \\
(N=8)\end{array}$ & $\begin{array}{l}\text { Healthy } \\
\text { human par- } \\
\text { ticipants } \\
\text { RDV 100 mg } \\
(N=26)\end{array}$ \\
\hline Plasma RDV & & \\
AUC $^{\mathrm{a}}(\mathrm{h} * \mathrm{ng} / \mathrm{mL})$ & $1430(16.1)$ & $1590(16.6)$ \\
$C_{\max }(\mathrm{ng} / \mathrm{mL})$ & $3350(11.6)$ & $2230(19.2)$ \\
PBMC GS-443902 $_{C_{24}(\mu \mathrm{M})}$ & $7.10(94.4)$ & $10.2(49.5)^{\mathrm{b}}$ \\
\hline
\end{tabular}

Values presented to three significant figures

$A U C$ area under the concentration-time curve, $A U C_{0-24}$ area under the concentration vs time curve over $24 \mathrm{~h}, A U C_{\text {tau }}$ area under the concentration versus time curve over the dosing interval, $C_{\max }$ maximum observed plasma concentration, $C V$ coefficient of variation, $N$ number in a population

a AUC: healthy rhesus monkeys $\mathrm{AUC}_{0-24}$; healthy human participants $\mathrm{AUC}_{\mathrm{tau}}$

${ }^{\mathrm{b}} N=25$ 
$\mathrm{mg} / \mathrm{kg} \times 2$ due to dose proportionality). Concentrations from the 100-mg doses were also comparable to those observed in rhesus monkeys receiving RDV $5-\mathrm{mg} / \mathrm{kg}$ doses for 7 days, and the doses associated with efficacy in SARS-CoV-2- and MERS-CoV-infected rhesus monkey models. The PK and safety of the proposed clinical regimen of RDV $200 \mathrm{mg}$ on day 1 , followed by $100 \mathrm{mg}$ once daily for up to 9 days were subsequently examined in the phase I study in healthy volunteers, described in Sect. 3.2.3.

\subsubsection{Clinical Dose PK and Safety Study}

The PK, safety, and tolerability of the RDV clinical dosing regimen (200-mg loading dose on day 1 followed by 100 $\mathrm{mg}$ maintenance IV doses for 4 or 9 days) was examined in a randomized, blinded, placebo-controlled, phase I study in healthy volunteers. Methods are detailed in the "Appendix". Briefly, IV RDV was administered as a 30-min infusion at a 200-mg loading dose on day 1 , followed by 100 -mg maintenance doses for 4 days in Cohort $1(n=10$; eight active, two placebo) and 9 days in Cohort $2(n=25 ; 20$ active and five placebo) to healthy participants. A total of 36 participants were randomized into the study and of those, 33 (91.7\%) completed the study drug and $30(83.3 \%)$ completed the study. The reasons for premature discontinuation of study drug $(n=3)$ were adverse event (AE, $n=1$; Cohort 1; Grade 1 nausea and paresthesia) and subject decision $(N=1$ in Cohort 1; $N=1$ in Cohort 2). Five participants withdrew consents and discontinued the study ( $n=4$ in Cohort 1 and $n=1$ in Cohort 2) and AE ( $n=1$ in Cohort 1). Baseline characteristics were generally balanced across cohorts and are presented in Table 2. Across both cohorts, the median age of participants was 31 years (range 20-44 years) and the majority of participants were male (80.6\%), white (61.1\%), and not Hispanic or Latino (94.4\%).

Overall, study drug was generally well tolerated. There were no serious AEs, Grade 3 or 4 AEs, or deaths reported in either study. All AEs were Grade 1 or 2 in severity. The most frequently reported AEs included infusion-site phlebitis (all in the RDV treatment groups of Cohort 2, 8 of 20 participants [40\%]), nausea (all in RDV treatment groups of Cohort 1: 2 of 9 participants [22.2\%] and Cohort 2: 2 of 20 participants [10\%]), and headache (Cohort 1: 2 of 9 participants [22.2\%] in the RDV treatment group; Cohort 2: 1 of 20 participants [5.0\%] in the RDV treatment group, 1 of 5 participants [20.0\%] in the placebo group). The majority of laboratory abnormalities were Grade 1 in severity. There were no graded alanine aminotransferase (ALT) abnormalities in Cohort 1. In Cohort 2, there were eight participants with Grade 1 and 1 subject with Grade 2 ALT abnormalities in the RDV treatment group. Within this cohort, mean ALT levels increased during RDV administration, peaked from days 10 to 13 , and started decreasing after day 14 . Transient Grade 1 aspartate aminotransferase (AST) abnormalities were also reported in four of the nine participants with graded ALT abnormalities. All graded ALT abnormalities resolved to a normal range by the follow-up visit.

Comparison of RDV PK revealed similar PK of RDV, GS-704277, and GS-441524 metabolites in plasma, and GS-443902 in PBMCs at days 5 (Cohort 1) and 10 (Cohort 2). With the exception of RDV maximum observed plasma concentration, which is highly dependent on infusion time, the $90 \%$ confidence intervals for the geometric least-square mean ratios for the primary pharmacokinetic parameters for all analytes crossed 100\% (Table S1 of the Electronic Supplementary Material). The data were also consistent with previously published data showing steady state reached on

Table 2 Subject demographics and baseline characteristics

\begin{tabular}{|c|c|c|c|c|c|}
\hline Characteristics & $\begin{array}{l}\text { Cohort } 1 \\
\text { RDV for } 5 \text { days } \\
(N=9)\end{array}$ & $\begin{array}{l}\text { Cohort } 2 \\
\text { RDV for } 10 \text { days } \\
(N=20)\end{array}$ & $\begin{array}{l}\text { Total RDV } \\
(N=29)\end{array}$ & $\begin{array}{l}\text { Total Placebo } \\
(N=7)\end{array}$ & $\begin{array}{l}\text { Overall } \\
(N=36)\end{array}$ \\
\hline Mean age (years; range) & $33(25-42)$ & $34(24-44)$ & $33(24-44)$ & $26(20-36)$ & $32(20-44)$ \\
\hline \multicolumn{6}{|l|}{ Sex } \\
\hline Male & $8(88.9 \%)$ & $16(80.0 \%)$ & $24(82.8 \%)$ & $5(71.4 \%)$ & $29(80.6 \%)$ \\
\hline Female & $1(11.1 \%)$ & $4(20.0 \%)$ & $5(17.2 \%)$ & $2(28.6 \%)$ & $7(19.4 \%)$ \\
\hline \multicolumn{6}{|l|}{ Race } \\
\hline White & $4(44.4 \%)$ & $13(65.0 \%)$ & $17(58.6 \%)$ & $5(71.4 \%)$ & $22(61.1 \%)$ \\
\hline Black or African American & $4(44.4 \%)$ & $7(35.0 \%)$ & $11(37.9 \%)$ & $1(14.3 \%)$ & $12(33.3 \%)$ \\
\hline \multicolumn{6}{|l|}{ Ethnicity } \\
\hline Hispanic or Latino & 0 & $1(5.0 \%)$ & $1(3.4 \%)$ & $1(14.3 \%)$ & $2(5.6 \%)$ \\
\hline Not Hispanic or Latino & $9(100.0 \%)$ & $19(95.0 \%)$ & $28(96.6 \%)$ & $6(85.7 \%)$ & $34(94.4 \%)$ \\
\hline Mean BMI $\left(\mathrm{kg} / \mathrm{m}^{2}\right.$; range $)$ & $24.0(20.2-28.5)$ & $25.3(19.6-30.4)$ & $24.9(19.6-30.4)$ & $23.2(19.4-25.6)$ & $24.6(19.4-30.4)$ \\
\hline
\end{tabular}

$B M I$ body mass index, $R D V$ remdesivir 
day 4 for GS-441524, and lack of accumulation for RDV, and GS-704277[18]. Therefore, the pharmacokinetic data for Cohorts 1 and 2 were combined to present a composite exposure estimate. The plasma concentrations and pharmacokinetic parameters of RDV, its intermediate metabolite GS-704277, and the nucleoside metabolite GS-441524 by dose following 30-min IV infusions of RDV in healthy participants (Cohorts 1 and 2 combined) are presented in Fig. 3 and Table 3. Pharmacokinetic data after the single 200-mg and multiple 100-mg RDV administrations were consistent with historical data [18]. Remdesivir was readily detectable in plasma and reached peak concentrations at the end of infusion (median time of occurrence of maximum observed plasma concentration $\sim 0.7 \mathrm{~h}$, consistent with the median duration of RDV infusion of 37-43 min). The rapid disappearance of RDV (median $t_{1 / 2} \sim 1 \mathrm{~h}$ ) was followed by transient exposure to the intermediate metabolite GS-704277 (median $t_{1 / 2} \sim 1.25 \mathrm{~h}$ ) and persistent plasma exposure to the nucleoside metabolite GS-441524 (median $t_{1 / 2} \sim 27 \mathrm{~h}$ ), and PBMC-associated pharmacologically active metabolite GS-443902 (median $t_{1 / 2} \sim 43 \mathrm{~h}$ ). The mean volume of distribution of RDV was approximately $93 \mathrm{~L}$, confirming RDV distribution to tissues; and the mean steady-state clearance
Fig. 3 Mean (standard deviation) of remdesivir (RDV), GS-704277, and GS-441524 plasma concentration vs time by dose following $30-\mathrm{min}$ intravenous infusion(s) of a single 200-mg dose or multiple 100-mg remdesivir doses in healthy subjects
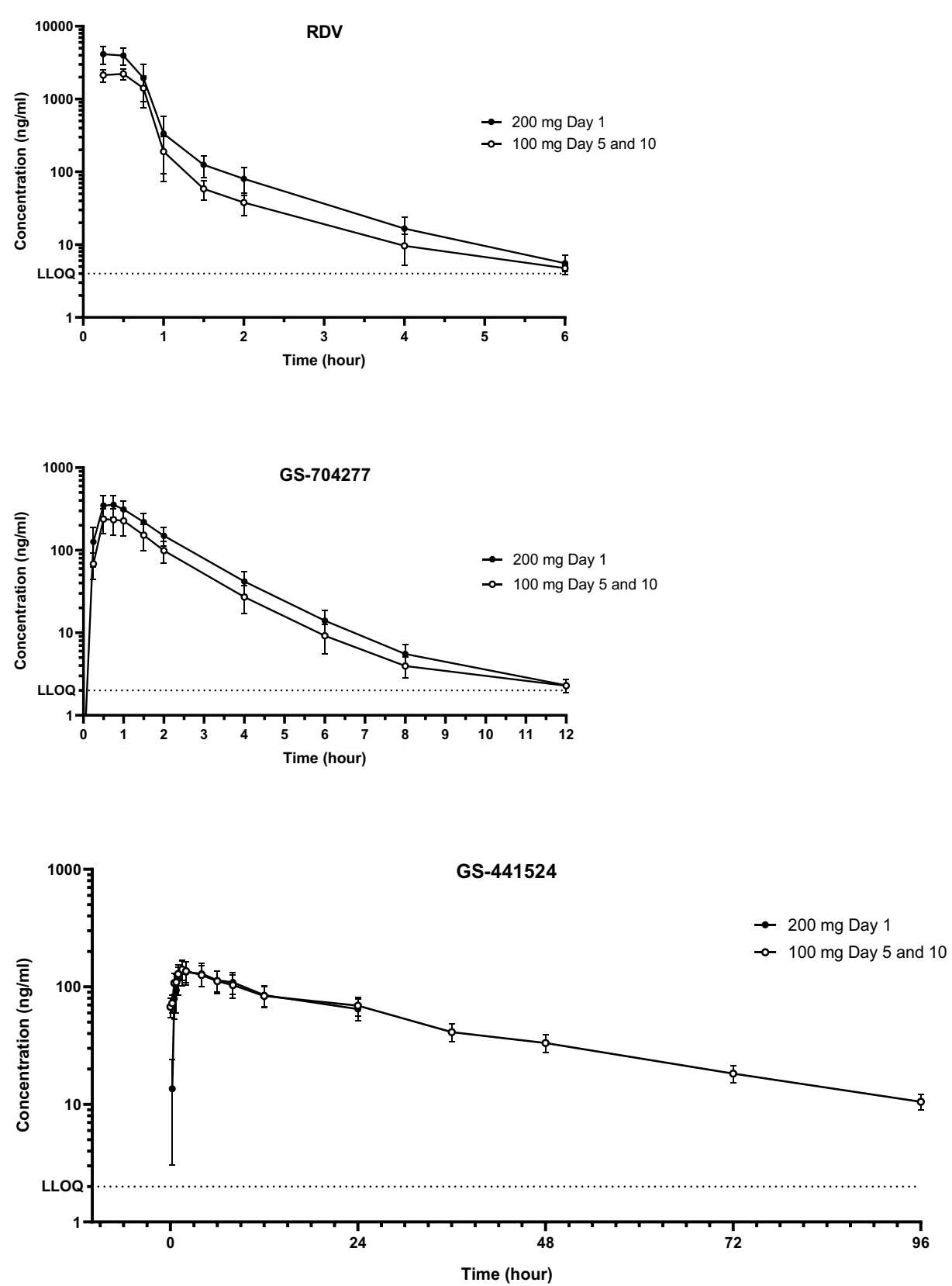
Table 3 Pharmacokinetic (PK) parameters of remdesivir (RDV), GS-441524, and GS-704277 in the multiple-dose study by dose following 30-min intravenous infusion(s) of $200 \mathrm{mg}$ RDV on day 1 followed by $100 \mathrm{mg}$ daily for 4 or 9 days in healthy participants

\begin{tabular}{lll}
\hline PK parameters $^{\mathrm{a}}$ & $\begin{array}{l}\text { Single RDV dose }(200 \mathrm{mg}) \\
\text { Day } 1 ; N=28\end{array}$ & $\begin{array}{l}\text { Multiple RDV } \\
\text { doses }(100 \mathrm{mg}) \\
\text { Days } 5 \text { and } 10 ; \\
=26\end{array}$ \\
\hline $\mathrm{RDV}$ & & \\
$C_{\max }, \mathrm{ng} / \mathrm{mL}$ & $4380(23.5)$ & $2230(19.2)$ \\
$T_{\max }, \mathrm{h}$ & $0.67(0.25,0.68)$ & $0.68(0.25,0.75)$ \\
$t_{1 / 2}, \mathrm{~h}$ & $0.90(0.80,1.03)$ & $0.96^{\mathrm{b}}(0.86,1.08)$ \\
$\mathrm{CL}_{\mathrm{ss}}, \mathrm{L} / \mathrm{h}$ & - & $65.1^{\mathrm{b}}(19.8)$ \\
$V_{\mathrm{z}}, \mathrm{L}$ & - & $92.6^{\mathrm{b}}(29.5)$ \\
$\mathrm{AUC}$ & & $1590^{\mathrm{b}}(16.6)$ \\
$\mathrm{GS}-441524$ & $2860(18.6)$ & $145(19.3)$ \\
$C_{\text {max }}, \mathrm{ng} / \mathrm{mL}$ & $143(21.5)$ & $69.2(18.2)$ \\
$C_{\text {tau }}, \mathrm{ng} / \mathrm{mL}$ & - & $1.51(1.50,2.00)$ \\
$T_{\max }, \mathrm{h}$ & $2.00(1.50,4.00)$ & $27.4(25.3,30.3)$ \\
$t_{1 / 2}, \mathrm{~h}$ & - & $2230(18.4)$ \\
$\mathrm{AUCC}$ & & \\
$\mathrm{GS}-704277$ & $2190(19.1)$ & $246(33.9)$ \\
$C_{\text {max }}, \mathrm{ng} / \mathrm{mL}$ & $370(29.3)$ & $0.75(0.75,0.78)$ \\
$T_{\max }, \mathrm{h}$ & $0.75(0.67,0.75)$ & $1.23(1.15,1.38)$ \\
$t_{1 / 2}, \mathrm{~h}$ & $1.27(1.14,1.45)$ & $462(31.4)$ \\
$\mathrm{AUC}$ & $698(25.9)$ & \\
\hline
\end{tabular}

Values presented to three significant figures

$A U C$ area under the concentration-time curve, $A U C_{0-24}$ area under the concentration vs time curve over $24 \mathrm{~h}, A U C_{\text {tau }}$ area under the concentration versus time curve over the dosing interval, $C L_{s s}$ steadystate clearance, $C_{\max }$ maximum observed plasma concentration, $C_{\text {tau }}$ observed drug concentration at the end of the dosing interval, $t_{1 / 2}$ terminal elimination half-life $T_{\max }$ time of occurrence of $\mathrm{C}_{\max }, C V$ coefficient of variation, $V_{z}$ volume of distribution

${ }^{a}$ Data are presented as mean (\%CV), except for $T_{\max }$ and $t_{1 / 2}$, which are presented as median (Q1, Q3)

${ }^{\mathrm{b}} N=25$ for $\mathrm{AUC}_{\mathrm{tau}}, t_{1 / 2}$

${ }^{\mathrm{c}} \mathrm{AUC}_{0-24}$ is presented for a single RDV dose $(200 \mathrm{mg})$ on day 1 ; $\mathrm{AUC}_{\mathrm{tau}}$ is presented for multiple RDV doses $(100 \mathrm{mg})$ on days 5 and 10

was approximately $65 \mathrm{~L} / \mathrm{h}$, demonstrating consistency with historical data.

GS-443902 PBMC pharmacokinetic parameters are presented in Table 4. High intracellular trough concentrations of the active triphosphate metabolite GS-443902 were observed in PBMCs following a single 200-mg dose or multiple 100-mg doses of IV RDV demonstrating efficient conversion from RDV into the triphosphate form.

Based on compilation of (1) pharmacokinetic and safety data from phase I studies, (2) nonclinical pharmacokinetic and efficacy data, and (3) the results of physiologically based pharmacokinetic (PBPK) modeling described elsewhere [25], the RDV clinical regimen of a 200-mg IV loading dose
Table 4 GS-443902 peripheral blood mononuclear cell (PBMC) pharmacokinetic (PK) parameters by dose following a 30-min intravenous infusion of $200 \mathrm{mg}$ of remdesivir (RDV) on day 1 followed by $100 \mathrm{mg}$ daily for 4 or 9 days in healthy participants

\begin{tabular}{lll}
\hline $\begin{array}{l}\text { GS-443902 } \\
\text { PBMC PK parameter }\end{array}$ & $\begin{array}{l}\text { Single RDV dose } \\
(200 \mathrm{mg}) \\
\text { Day 1 } \\
(N=28)\end{array}$ & $\begin{array}{l}\text { Multiple RDV } \\
\text { dose }(100 \mathrm{mg}) \\
\text { Days 5 and 10 } \\
(N=26)^{\mathrm{b}}\end{array}$ \\
\hline $\mathrm{AUC}^{\mathrm{C}}, \mathrm{h}^{*} \mu \mathrm{M}$ & $157(32.9)$ & $240(25.4)$ \\
$C_{\text {max }}, \mu \mathrm{M}$ & $9.80(46.6)$ & $14.6(40.6)$ \\
$C_{\mathrm{tau}}, \mu \mathrm{M}$ & - & $10.2(49.5)$ \\
$t_{1 / 2}, \mathrm{~h}$ & - & $43.4(38.7,48.9)$
\end{tabular}

Values presented to three significant figures

$A U C$ area under the concentration-time curve, $A U C_{0-24}$ area under the concentration vs time curve over $24 \mathrm{~h}, A U C_{\text {tau }}$ area under the concentration vs time curve over the dosing interval, $C_{\max }$ maximum observed plasma concentration, $C_{t a u}$ observed drug concentration at the end of the dosing interval, $C V$ coefficient of variation, $t_{1 / 2}$ terminal elimination half-life

${ }^{a}$ Data are presented as mean $(\% \mathrm{CV})$, except for $t_{1 / 2}$, which is presented as median $(\mathrm{Q} 1, \mathrm{Q} 3)$

${ }^{\mathrm{b}} N=25$ for $C_{\text {tau }}$, and $N=20$ for $\mathrm{t}_{1 / 2}$

${ }^{\mathrm{c}} \mathrm{AUC}_{0-24}$ is presented for a single RDV dose $(200 \mathrm{mg})$ on day 1 ; $\mathrm{AUC}_{\text {tau }}$ is presented for multiple RDV doses $(100 \mathrm{mg})$ on days 5 and 10

on day 1 followed by RDV 100-mg once-daily maintenance doses for up to 9 days (days 2-10) has been evaluated in clinical trials for the treatment of patients with COVID-19 at least 12 years of age, weighing at least $40 \mathrm{~kg}$ [26-29]. For the treatment of patients weighing $<40 \mathrm{~kg}$ with COVID-19 (14 days old, $\geq 2.5 \mathrm{~kg}$, born full term [gestational age $>37$ weeks] and with serum creatinine $<0.6 \mathrm{mg} / \mathrm{dL}$ ), the dose being evaluated in an ongoing efficacy, safety, and pharmacokinetic study of RDV is as follows: a single RDV 5-mg/ $\mathrm{kg}$ IV loading dose on day 1 followed by RDV $2.5 \mathrm{mg} / \mathrm{kg} \mathrm{IV}$ once-daily maintenance doses for up to 9 days (days 2-10) [30]. Remdesivir has also been administered to pediatric patients (birth to 18 years of age) with severe COVID-19 under Gilead's compassionate use program [31].

\section{Pharmacodynamics/C-QT Analysis}

In 2015, the International Conference on Harmonization E14 Guidance allowed C-QT modeling to be used as the primary analysis for assessing the QTc interval prolongation risk of new drugs [32]. In this model, all available data across all doses are used to characterize the potential for a drug to influence QTc [33].

A C-QT analysis for remdesivir was conducted in lieu of a TQT study using phase I data in heathy adult volunteers who received daily 60-min infusions of IV RDV 150 
mg for 7 or 14 days 18 . In this analysis, the effect of plasma concentrations of RDV and its metabolites (GS-441524 and GS-704277) on baseline-adjusted QTcF intervals were evaluated after adjusted for visit, time points, and treatment effects. The exposures achieved in this study were wide enough to cover the therapeutic exposures at the proposed clinical regimen of $200 \mathrm{mg}$ on day 1 followed by $100 \mathrm{mg}$ once daily for up to 10 days as observed in the clinical pharmacokinetic/safety study described in Sect. 3.2.3.

The C-QT modeling approach was based on the scientific white paper on C-QT modeling [29]. The predicted mean $\Delta \Delta \mathrm{QTcF}$ and corresponding two-sided $90 \%$ confidence interval from the final model were estimated for two sets of therapeutic concentrations of RDV, GS-441524, and GS-704277 (corresponding to the concentrations observed on a single dose of $200 \mathrm{mg}$ and multiple doses of $100 \mathrm{mg}$, respectively), which showed that both the upper bounds were below the 10-ms threshold.

The final model was selected from eight models based on the Akaike information criterion (AIC) values. The model with no interaction terms and with random intercept and slopes on plasma concentrations using a heterogenous compound symmetry covariance structure had the smallest AIC value and thus was selected as the final model. The estimates for the parameters in the final model computed using the restricted maximum likelihood estimation method. The final model could be represented mathematically by:

$$
\begin{aligned}
& \Delta \mathrm{QTcF}_{i j k}=\left(\theta_{0}+\eta_{0, i}\right)+\theta_{1} \operatorname{Trt}_{i}+\left(\theta_{2}+\eta_{2, i}\right) \mathrm{GS} \mathrm{G}_{34} \\
& +\left(\theta_{3}+\eta_{3, i}\right) \mathrm{GS}_{41524} \\
& +\sum_{j} \theta_{5, j} \text { Visit }_{j}+\sum_{k} \theta_{6, k} \operatorname{Time}_{k}+\theta_{7, i} \mathrm{QTCF}_{i, j=1, k=0}+\varepsilon_{i j k},
\end{aligned}
$$

where $\Delta \mathrm{QTcF}_{i j k}$ is the $\Delta \mathrm{QTcF}$ for subject $i$ at visit $j$ and time $k, \operatorname{Trt}_{i}$ is the treatment for subject $i$ (i.e., 0 for placebo and 1 for RDV), and $G S 5734_{i j k}$ is the standardized parent RDV concentration for subject $i$ at visit $j$ and time $k$. Similarly, GS441524 $4_{i j k}$ is the standardized metabolite GS-441524 concentration and GS704277 $i j k$ is for the standardized metabolite GS-704277 concentration. Visit ${ }_{j}$ is the nominal visit $j$ (i.e., day 1, day 7, vs day 14). Time ${ }_{k}$ is the nominal time point $k$. $\mathrm{QTcF}_{i, j=1, k=0}$ is the standardized baseline QTcF for subject $i$, which is the average of the three sets of triplicate pre-dose measurements measured on day 1 .

Two sensitivity analyses were conducted to examine the robustness of the results from the final model. The sensitivity analyses evaluated results from a two-way combination of the plasma concentrations models with the lowest AIC, and from univariate models with a single plasma concentration with the lowest AIC. Results from both sensitivity analyses performed very similar to the results from the final model and showed consistently upper two-sided $90 \%$ CI bounds to be below the $10-\mathrm{ms}$ threshold, indicating that RDV, GS 441524, and GS-704277 do not cause QTcF interval prolongation at therapeutic concentrations. Pending data from the ongoing phase I studies in participants with renal and hepatic impairment, a thorough QT study with a supratherapeutic remdesivir dose is planned.

\section{Drug Interaction Potential}

\subsection{In Vitro Characterization of the Drug Interaction Potential of RDV}

In vitro studies (e.g., human hepatic microsomes, hepatic hepatocytes, transfected cell lines, and recombinant human enzymes) to assess the potential for drug interactions with RDV via major drug-metabolizing enzymes and transporters have been conducted (data on file) [11]. As a precipitant of DDIs, there was no potential for induction of enzymes or transporters via the pregnane $\mathrm{X}$ receptor or aryl hydrocarbon receptor detected in reporter cell lines by RDV. While RDV was identified as a weak inhibitor of CYP3A4, organic anion transporter protein1B1 (OATP1B1), OATP1B3, and MATE1 in vitro, its potential to be the perpetrator of clinically significant drug-drug interactions (DDIs) is limited by its route of administration, transient exposure, and rapid clearance. No additional potential clinically relevant interactions have been identified for RDV, GS-704277, or GS-441524 in the in vitro studies.

As an object of DDIs, data from in vitro screening assays suggested that pathways involving CYP isozymes or hepatic transporters are not likely to be important in the disposition of RDV or as a mechanism of drug interactions. While RDV can be metabolized by CYP2C8, CYP2D6, and CYP3A using recombinant enzyme systems, further studies in hepatocytes confirmed that CYP3A is primarily responsible for the CYP-dependent hepatic metabolism of RDV ( $10 \%$ of total hepatic clearance). The intracellular activation pathway of RDV is esterase mediated (Sect. 3.1.3) and is not likely to be inhibited by commonly used drugs. In vitro, RDV is a substrate for OATP1B1 and P-glycoprotein, and GS-704277 is a substrate for OATP1B1 and OATP1B3. However, the impact of these transporters on RDV disposition is again likely minimized by the parenteral route of administration. 
Table 5 Predicted fold change in remdesivir (RDV) area under the curve with inhibition or induction of hepatic transporters

Predicted effect of rifampin on RDV AUCR using the Kirby 2010 Equation 8 Model [30]

Simulated scenarios for rifampin induction of CES-1 and CatA assuming a 15-fold induction Kirby 2010 Equation 8 predicted RDV AUCR of CYP3A

Assumptions: $f_{\text {hep }}=0.9, f_{\mathrm{m}, \mathrm{CES} 1}=0.8, f_{\mathrm{m}, \mathrm{CatA}}=$ $0.1, f_{\mathrm{m}, \mathrm{CYP} 3 \mathrm{~A}}=0.1$

Magnitude of induction of $f_{\text {Clint,CES1 }}^{\text {Hep }} \quad f_{\text {Clint,CAtA }}^{\text {Hep }} \quad f_{\text {Clint,CYP3A }}^{\text {Hep }}$

$\mathrm{EH}=0.6$

$\mathrm{EH}=0.7$

$\mathrm{EH}=0.8$ CES-1 and CatA

None
2-fold
4-fold
8 -fold

1
2
4
8

$\begin{array}{ll}1 & 15 \\ 2 & 15 \\ 4 & 15 \\ 8 & 15\end{array}$

15
15
15
15

0.78
0.74
0.70
0.67

0.84

0.81

0.78

0.75

Predicted effect of complete CYP3A inhibition, or 10-fold CYP3A induction of RDV AUCR using the Kirby 2010 Equation 8 Model [30]

\begin{tabular}{|c|c|c|c|c|c|}
\hline \multirow[b]{3}{*}{ CYP3A DDI scenario } & \multirow[b]{3}{*}{$f_{\text {Clint,CYP3A }}^{\text {Hep }}$} & \multicolumn{3}{|c|}{ RDV AUCR } & \multirow{3}{*}{$\begin{array}{l}\text { Midazolam AUCR } \\
\text { Assumptions: } f_{\mathrm{hep}}=1.0, f_{\mathrm{m}, \mathrm{CYP} 3 \mathrm{~A}}=0.93 \\
\text { Low EH assuming PO administration }\end{array}$} \\
\hline & & \multicolumn{3}{|c|}{ Assumptions: $f_{\text {hep }}=0.9, f_{\mathrm{m}, \mathrm{CYP} 3 \mathrm{~A}}=0.1$} & \\
\hline & & $\mathrm{EH}=0.6$ & $\mathrm{EH}=0.7$ & $\mathrm{EH}=0.8$ & \\
\hline Complete inhibition & 0 & 1.04 & 1.03 & 1.02 & 14.3 \\
\hline 5-fold induction & 5 & 0.90 & 0.92 & 0.95 & 0.21 \\
\hline 10-fold induction & 10 & 0.83 & 0.87 & 0.91 & 0.11 \\
\hline 15-fold induction & 15 & 0.78 & 0.84 & 0.89 & 0.07 \\
\hline
\end{tabular}

$A U C R$ area under the concentration-time curve ratio, CatA cathepsin A, CES1 carboxylesterase 1, CYP cytochrome P450, DDI drug-drug interaction, $E H$ hepatic extraction ratio of the victim drug, $f_{\text {Clint }}$ the combined effect of inactivation, induction, and inhibition or net change in intrinsic clearance, $f_{\text {hep }}$ the fraction of intravenous clearance that is hepatic elimination, $f_{\mathrm{m}, \text { CYPi }}$ the fraction of hepatic clearance of the victim drug via a given enzymatic pathway, $P O$ oral

\subsection{In Vivo Prediction of the Drug Interaction Potential of RDV}

Clinical DDI studies of RDV have not been conducted to date. A mathematical prediction of the DDI liability of RDV, as an object of DDIs, was therefore conducted using available in vitro data and phase I data in healthy volunteers (Table 5). Because of the IV route of administration and moderate-to-high extraction ratio (0.6-0.8), the magnitude of effect of inducers or inhibitors on the PK of RDV will be substantially attenuated compared with what would be expected if RDV had a low hepatic extraction ratio [34]. Specifically, when accounting for the known level of CYP3A induction by rifampin, the strong inducer of multiple drug-metabolizing enzymes, and a four-fold induction of esterase activity (carboxylesterase 1 and cathepsin A), the reduction in RDV exposure is expected to be $30 \%$. Similarly, complete CYP3A inhibition would be expected to increase RDV exposure by only $4 \%$ compared to a 20-fold increase in the exposure of midazolam, a probe CYP3A substrate. Based on these predictions, the use of weak or moderate CYP3A inducers and strong CYP3A inhibitors were permitted in the RDV phase III clinical program. The DDI evaluation between rifampin and RDV is planned.
To evaluate the potential for RDV to inhibit drug-metabolizing enzymes and transporters in vivo, a physiologically based pharmacokinetic model that captures the in vivo PK and in vitro inhibition potency of RDV was developed using SimCYP (version 18; Certara, Sheffield, UK). Physicochemical properties and available absorption, distribution, metabolism and elimination data (Sect. 2) were inputted and the resulting model was refined to accurately reproduce observed healthy volunteer PK after administration of the therapeutic RDV regimen (Sect. 3.2.3). In vitro unbound inhibition constants for CYP3A, OATP1B1, OATP1B3, $\mathrm{BCRP}$, and MATE1 were inputted and the change in midazolam (CYP3A), pravastatin (OATP), rosuvastatin (OATP/ $\mathrm{BCRP}$ ), and metformin (MATE1) probe exposure (AUC/ maximum observed plasma concentration) was predicted. All probe models were used as provided by SimCYP. For these simulations, the timing of RDV administration relative to probe drug was optimized to predict the highest potential DDI, which roughly corresponded to administration of RDV so that the end of infusion occurred at the probe maximum observed plasma concentration. Coadministration of $\mathrm{RDV}$ is predicted to increase pravastatin, rosuvastatin, and metformin AUC by $<5 \%$, and midazolam AUC by $<10 \%$, providing strong evidence that RDV is unlikely to be a clinically significant inhibitor of drug-metabolizing enzymes or 
transporters in patients infected with COVID-19 at therapeutic RDV doses.

\section{Ongoing Work: PK in Special Populations}

\subsection{Pediatrics}

In children aged $<18$ years, most of the reported cases of COVID-19 in the USA appear to be asymptomatic or mild. There have been reports from Europe and North America describing clusters of children and adolescents with COVID19-associated multi-system inflammatory conditions, similar to Kawasaki's disease [35, 36]. On 14 May, the Centers for Disease Control and Prevention provided a case definition for multi-system inflammatory syndrome in children in an advisory board. Current treatment options available consist of supportive care directed against the underlying inflammatory process [37]. Specific dosing guidelines for pediatric patients with COVID-19 is needed.

\subsubsection{Adolescents ( $\geq 40 \mathrm{~kg})$}

Drug disposition pathways, including renal elimination, hepatic metabolism, or transport, reach adult activity levels by the age of 12 years. Hence, similar doses and formulations are recommended for adults and adolescents for the same condition or disease [38]. Although knowledge of COVID-19 is still evolving, the PK of RDV is expected to be similar between adolescents (weighing at least $40 \mathrm{~kg}$ ) and adults. Remdesivir dose selection in adolescent participants was determined using PBPK modeling. Briefly, the model was developed to characterize the PK of RDV GS-704277 and GS-441524, in adults. The adult PBPK model was then used to predict exposure in adolescents, accounting for agedependent changes in organ volume or size (liver and kidney), esterase expression, plasma protein binding, and organ blood flow [25]. Simulations demonstrated that the use of an adult dosage regimen in adolescent participants, weighing at least $40 \mathrm{~kg}$, is predicted to maintain RDV and GS-441524 exposures generally within the expected steady-state exposure range following the adult dosage regimen $[11,25]$.

\subsubsection{Children $(2.5$ to $<40 \mathrm{~kg})$}

The adult PBPK model was used to predict pediatric exposures of RDV and metabolites and compared to observed exposures from the adult phase I program. These simulations indicated that a weight-based regimen of $5 \mathrm{mg} / \mathrm{kg}$ on day 1 , followed by $2.5 \mathrm{mg} / \mathrm{kg}$ once daily for up to 9 days in pediatric patients weighing 2.5 to $<40 \mathrm{~kg}$ is predicted to maintain exposures of RDV and metabolites generally within the expected adult steady-state exposure range following an adult therapeutic dosage regimen. Full details of this analysis are presented elsewhere [25]. The safety, efficacy, and PK of this regimen in pediatric patients with moderate-tosevere COVID-19 are also being evaluated in the phase II/ III clinical trial [30].

\subsection{Hepatic Impairment}

Liver impairment, as manifested by AST and ALT elevations, has been reported in patients with COVID-19 and may be caused directly by viral infection of liver cells. Recent reports suggested that $2-11 \%$ patients with COVID-19 have underlying chronic liver disease [39]. Therefore, understanding the PK in patients with hepatic impairment is essential.

Most of RDV elimination is via the nonrenal route. The primary metabolic route for RDV is via carboxylesterase 1-mediated hydrolase cleavage, the ubiquitous high-capacity system that is not expected to be markedly affected by mild hepatic impairment. This is further supported by data for known sensitive carboxylesterase 1 substrates, for which exposure was not altered in participants with mild hepatic impairment [40-42]. The effect of moderate or severe hepatic impairment on the PK of RDV will be examined in a planned phase I study.

\subsection{Renal Impairment}

Kidney involvement is frequent in COVID-19; from mild proteinuria to acute kidney injury affecting the critically ill patients ( 20 to $40 \%$ of patients admitted to intensive care). Moreover, around $20 \%$ of patients admitted to an intensive care unit with COVID-19 require renal replacement therapy [43].

The PK of RDV has not been evaluated in patients with renal impairment. However, as the acute reduction in renal function was commonly observed in patients with COVID19 at hospital admission, patients with an eGFR $\geq 30 \mathrm{~mL} /$ min (mild-to-moderate renal disease) were included in the phase III clinical development program and received RDV for the treatment of COVID-19 with no dose adjustment. Remdesivir may be administered to patients with an eGFR $\geq 30 \mathrm{~mL} / \mathrm{min}$ [11]. The safety and efficacy of RDV have not been assessed in patients with an eGFR $<30 \mathrm{~mL} / \mathrm{min}$, precluding RDV use in this patient population. A dedicated phase I study evaluating the PK and short-term safety of RDV in non-COVID-infected patients with varying degrees of chronic renal impairment including kidney failure is ongoing. 


\section{Conclusions}

Overall, this article summarizes available PK and safety of RDV administered to healthy volunteers in first-in-human single- and multiple-dose studies, a phase I healthy-volunteer study investigating the proposed clinical dose regimen for the treatment of COVID-19, rationale for dose selection (adult and pediatric), pharmacodynamics/C-QT analysis, the potential DDI liability of RDV, and discussion of ongoing studies in special populations (pediatrics, hepatic impairment, renal impairment).

Remdesivir is an important therapeutic option for patients with COVID-19 based on the described clinical pharmacology properties, safety profile, potency, and low DDI potential. Ongoing clinical pharmacology studies focus on the characterizing effect of renal and hepatic disfunction on the PK of remdesivir, characterizing DDI with strong CYP3A inducers, and will further support the use of RDV for the treatment of COVID-19.

Given the high incidence of hepatic and renal involvement in COVID-19 and the generally poor treatment outcomes in this subgroup of patients, it is important to characterize the relationship between hepatic function and RDV disposition. Liver comorbidities have been reported in $14-53 \%$ of patients with COVID-19 and appear to correspond to the severity of the disease; patients with severe COVID-19 had higher rates of abnormal liver function including increased ALT and increased AST compared to those with non-severe disease [44, 45]. Moreover, recent reports showed that about $2-11 \%$ of patients with COVID19 had underlying chronic liver disease. Cases of acute liver injury have been reported and are associated with higher mortality [46]. Patients with COVID-19 with ALT and AST greater than or equal to five times the upper limit of normal received a 200-mg dose of RDV on day 1 followed by $100 \mathrm{mg}$ for up to 10 days without dose adjustment in the phase III program [11].

Kidney involvement is frequent in COVID-19; from mild proteinuria to acute kidney injury affecting the critically ill patients ( 20 to $40 \%$ of patients admitted to intensive care) [43]. Moreover, around $20 \%$ of patients admitted to an intensive care unit with COVID-19 require renal replacement therapy. As the reduction in renal function was commonly observed in patients with COVID-19 at hospital admission, patients with an eGFR rate $\geq 30 \mathrm{~mL} /$ min (mild-to-moderate renal disease) were included in the phase III clinical development program and received RDV for the treatment of COVID-19 with no dose adjustment. However, because phase III safety data in patients with acute renal disease may not be directly translatable to patients with chronic kidney disease, further assessment of RDV safety and PK in this subpopulation is planned.
The evaluation of the PK, safety, and potential efficacy of RDV in the pediatric population with COVID-19 is urgently needed. Although the minority of children display severe COVID-19, reports of hospitalized pediatric patients from neonates to adolescents have emerged. In those with severe disease, symptoms and radiological findings are similar to those of adults. Furthermore, underlying conditions such as pulmonary disease, immunocompromised state, or co-existing respiratory infections might predispose to severe respiratory disease. The ongoing study of RDV in a pediatric population aims to characterize the PK of RDV and metabolites in all age groups and weight bands, from adolescent to pre-term neonates.

\section{Appendix}

\section{Methods for Phase I Clinical Dose Selection Study}

\section{Study Population}

Protocols and informed consent for this study were approved by the study center's institutional review board, and participants provided written consent before study participation. This study was a randomized, blinded, placebo-controlled, phase I study to evaluate the pharmacokinetics, safety, and tolerability of multiple intravenous doses of remdesivir (RDV) compared with placebo in healthy participants conducted at a single center in St Paul, MN, USA. Eligible participants were healthy male and non-pregnant, non-lactating female participants of nonchildbearing potential, 18-45 years of age with a body mass index between 18 and $30 \mathrm{~kg} / \mathrm{m}^{2}$. Participants did not participate in more than one cohort of the study.

Major inclusion criteria included healthy participants based on medical history/physical examinations/laboratory evaluations, normal 12-lead electrocardiogram, creatinine clearance $>90 \mathrm{~mL} / \mathrm{min}$, no evidence of human immunodeficiency virus, hepatitis B virus, or hepatitis $\mathrm{C}$ virus infection, and use of at least two forms of contraception, including an effective barrier method. Exclusion criteria included plasma and blood donation within 7 and 56 days of study entry, respectively, active medical illness, use of prescription drugs within 28 days of study drug dosing (except vitamins, acetaminophen, ibuprofen, and/or hormonal contraceptives).

\section{Study Design}

Approximately 36 participants were enrolled into two sequential cohorts. Participants were not allowed to participate in more than one cohort. Cohort 1 enrolled eight 
active and two placebo to match and Cohort 2 enrolled 20 active and 5 placebo to match. Remdesivir was administered intravenously over a $30-\mathrm{min}$ period once daily at a $200-\mathrm{mg}$ loading dose on day 1 , followed by a $100-\mathrm{mg}$ maintenance dose for 4 days in Cohort 1 and 9 days in Cohort 2. All participants returned 7 days after discharge for an in-clinic follow-up visit. Participants were discharged on day 12 for Cohort 1 and day 17 for Cohort 2 .

\section{Pharmacokinetic Evaluation}

Intensive plasma and peripheral blood mononuclear cell pharmacokinetic (PK) sampling occurred on day 1 prior to dosing and post-dose PK sampling was performed over $24 \mathrm{~h}$. On the last day of dosing for each cohort (day 5 of Cohort 1 or day 10 of Cohort 2), intensive PK sampling was performed over $96 \mathrm{~h}$ post-dose.

\section{Bioanalytical Procedures}

Plasma concentrations of RDV, GS-704277, and GS-441524 were determined using a validated liquid chromatography tandem mass spectroscopy method with multiple reaction monitoring and electrospray ionization in the positive mode (QPS; LLC (Newark, DE, USA). Quantification was performed using multiple reaction monitoring of the transitions $\mathrm{m} / \mathrm{z}, 603.3 \rightarrow 402.2$ and $\mathrm{m} / \mathrm{z} 606.3 \rightarrow 402.2$ for RDV and an isotopically labeled internal standard (GS-829143), $m / z, 441.1 \rightarrow 150.1$ and $m / z 444.1 \rightarrow 150.1$ for GS-704277 and an isotopically labeled internal standard (GS-829466), $\mathrm{m} / \mathrm{z}, 292.2 \rightarrow 202.2$ and $\mathrm{m} / \mathrm{z} 295.2 \rightarrow 205.2$ for GS-441524 and an isotopically labeled internal standard (GS-828840), respectively. The bioanalytical method was validated over the calibrated ranges of $4-4000 \mathrm{ng} / \mathrm{mL}$ for RDV, 2-2000 $\mathrm{ng} / \mathrm{mL}$ for GS-704277, and 2-2000 ng/mL for GS-441524, respectively. Inter-assay precision, based on coefficient of variation for RDV, GS-704277, and GS-441524, had a range of 2.1-5.3\%, and accuracy, based on inter-assay percent relative error for RDV, GS-704277, and GS-441524, had a range of -9.8 to $9.5 \%$. All samples were analyzed in the timeframe supported by frozen stability storage data.

Peripheral blood mononuclear cell concentrations of GS-443902 (the active triphosphate) were determined using a validated liquid chromatography tandem mass spectroscopy method. This method involved cell lysis extraction of GS-443902 and its isotopically labeled internal standard (GS-829492) from human PBMCs. Quantification was performed using multiple reaction monitoring of the transitions $\mathrm{m} / \mathrm{z}, 532.2 \rightarrow 202.2$ for GS-443902 and $\mathrm{m} / \mathrm{z} 535.0 \rightarrow 205.0$ for an isotopically labeled internal standard (GS-829492). The bioanalytical method was validated over the calibrated range of 5-2500 ng/mL. Inter-assay precision and accuracy had ranges of $1.8-4.5 \% \mathrm{CV}$, and from -10.0 to $-0.9 \% \mathrm{RE}$, respectively. All samples were analyzed in the timeframe supported by frozen stability storage data.

\section{Safety Analyses}

During and following dosing, safety and tolerability were assessed through the reporting of treatment-emergent adverse events, clinical laboratory tests (hematology profile, chemistry profile, and urinalysis), physical examinations, vital signs, serum pregnancy tests (female participants) review of concomitant medications, and electrocardiograms at various time points during the study.

\section{Pharmacokinetic Analyses}

Pharmacokinetic parameters were estimated using noncompartmental methods using a linear log trapezoidal method for area under the plasma concentration-time curve estimation (WinNonlin 7.0; Pharsight Corp., St Louis, MO, USA). Pharmacokinetic parameters assessed included area under the concentration vs time curve from time zero to the last quantifiable concentration, the area under the concentration vs time curve over $24 \mathrm{~h}$, the area under the concentration-time curve over a dosing interval (at steady state; $\mathrm{AUC}_{\mathrm{tau}}$ ), maximum observed plasma concentration, and time of occurrence of maximum observed plasma concentration, terminal elimination half-life, clearance, and volume of distribution

\section{Statistical Analyses}

The PK analysis set included all participants who received at least one dose of the study drug and had at least one nonmissing post-dose concentration. The safety population included all participants who received at least one dose of RDV or placebo. No formal power or sample size calculations were used to determine cohort size in these phase I studies. Subject demographics and baseline characteristics, plasma and peripheral blood mononuclear cell PK parameters, and safety data were summarized by descriptive statistics for continuous data and by the number and percentage of participants for categorical data. Pharmacokinetic data presentation by dose was supported by an analysis of variance.

Supplementary Information The online version contains supplementary material available at https://doi.org/10.1007/s40262-021-00984-5. 
Acknowledgements We thank the investigators and coordinators at the participating centers and the participants who participated in these studies.

\section{Declarations}

Funding This was a Gilead Sciences initiated study.

Conflict of interest Rita Humeniuk, Anita Mathias, Brian J. Kirby, Justin D. Lutz, Huyen Cao, Anu Osinusi, Darius Babusis, Danielle Porter, Xuelian Wei, John Ling, Y. Sunila Reddy, and Polina German are employees of Gilead and hold stocks/shares in the company.

Ethics approval The study protocol and informed consent documents were reviewed and approved by a duly constituted institutional review board before study initiation in accordance with the basic principles defined in the US 21 CFR Part 312.20 and the principles enunciated in the Declaration of Helsinki.

Consent to participate Participants provided written consent before study participation.

Consent for publication All authors consented to the publication of this article.

Availability of data and material Data that support the findings of this study are included in this published article (and its "Appendix"). Any additional data generated are available from the corresponding author upon reasonable request.

Code availability The code is available under request.

Author contributions RH, AM, BJK, JDL, HC, AO, DB, DP, XW, JL, YSR, and PG contributed significantly to the design, conduct, analyses, and interpretation of data and were involved in the preparation, review, and approval of this article.

Open Access This article is licensed under a Creative Commons Attribution-NonCommercial 4.0 International License, which permits any non-commercial use, sharing, adaptation, distribution and reproduction in any medium or format, as long as you give appropriate credit to the original author(s) and the source, provide a link to the Creative Commons licence, and indicate if changes were made. The images or other third party material in this article are included in the article's Creative Commons licence, unless indicated otherwise in a credit line to the material. If material is not included in the article's Creative Commons licence and your intended use is not permitted by statutory regulation or exceeds the permitted use, you will need to obtain permission directly from the copyright holder. To view a copy of this licence, visit http://creativecommons.org/licenses/by-nc/4.0/.

\section{References}

1. Humeniuk R, Mathias A, Cao H, Osinusi A, Shen G, Chng E, et al. Safety, tolerability, and pharmacokinetics of remdesivir, an antiviral for treatment of COVID-19, in healthy subjects. Clin Transl Sci. 2020;13(5):896-906. https://doi.org/10.1111/cts. 12840.

2. WHO. Timeline of WHO's response to COVID-19. https://www. who.int/news-room/detail/29-06-2020-covidtimeline. Accessed 16 Aug 2020.
3. Vellingiri B, Jayaramayya K, Iyer M, Narayanasamy A, Govindasamy V, Giridharan B, et al. COVID-19: a promising cure for the global panic. Sci Total Environ. 2020;725:138277.

4. Harapan H, Itoh N, Yufika A, et al. Coronavirus disease 2019 (COVID-19): a literature review. J Infect Public Health. 2020;13:667-73.

5. Rothan HA, Byrareddy SN. The epidemiology and pathogenesis of coronavirus disease (COVID-19) outbreak. J Autoimmun. 2020;109:102433.

6. CDC. Interim clinical guidance for management of patients with confirmed coronavirus disease (COVID-19). Available from: https://www.cdc.gov/coronavirus/2019-ncov/hcp/clinical-guida nce-management-patients.html. Accessed 13 Aug 2020.

7. CDC. Assessing risk factors for severe COVID-19 illness. https:// www.cdc.gov/coronavirus/2019-ncov/covid-data/investigationsdiscovery/assessing-risk-factors.html. Accessed 13 Aug 2020.

8. NIH. COVID-19 treatment guidelines. https://www.covid19tre atmentguidelines.nih.gov/whats-new/. Accessed 29 Nov 2020.

9. FDA. News release. https://www.fda.gov/news-events/press-annou ncements/coronavirus-covid-19-update-fda-authorizes-monoc lonal-antibody-treatment-covid-19. Accessed 29 Nov 2020.

10. FDA. News release. https://www.fda.gov/news-events/press-annou ncements/coronavirus-covid-19-update-fda-authorizes-monoc lonal-antibodies-treatment-covid-19. Accessed 29 Nov 2020.

11. Veklury (remdesivir): US prescribing information. https://www. accessdata.fda.gov/drugsatfda_docs/label/2020/214787Orig1s000 lbl.pdf. Accessed 7 Dec 2020.

12. Sheahan TP, Sims AC, Graham RL, et al. Broad-spectrum antiviral GS-5734 inhibits both epidemic and zoonotic coronaviruses. Sci Transl Med. 2017;9:eaal3653.

13. Lo MK, Jordan R, Arvey A, et al. GS-5734 and its parent nucleoside analog inhibit filo-, pneumo-, and paramyxoviruses. Sci Rep. 2017;7:43395.

14. Warren TK, Jordan R, Lo MK, et al. Therapeutic efficacy of the small molecule GS-5734 against Ebola virus in rhesus monkeys. Nature. 2016;531:381-5.

15. Gordon CJ, Tchesnokov EP, Feng JY, Porter DP, Gotte M. The antiviral compound remdesivir potently inhibits RNA-dependent RNA polymerase from Middle East respiratory syndrome coronavirus. J Biol Chem. 2020;295:4773-9.

16. Gordon CJ, Tchesnokov EP, Woolner E, et al. Remdesivir is a direct-acting antiviral that inhibits RNA-dependent RNA polymerase from severe acute respiratory syndrome coronavirus 2 with high potency. J Biol Chem. 2020;295:6785-97.

17. Tchesnokov EP, Gordon CJ, Woolner E, et al. Template-dependent inhibition of coronavirus RNA-dependent RNA polymerase by remdesivir reveals a second mechanism of action. J Biol Chem. 2020. https://doi.org/10.1074/jbc.AC120.015720.

18. FDA. News release. https://www.fda.gov/news-events/ press-announcements/fda-approves-first-treatment-covid-19. Accessed 7 Dec 2020

19. Gliead. Gilead announces approval of Veklury ${ }^{\circledR}$ (remdesivir) in Japan for patients with severe COVID-19. https://www.gilead. com/news-and-press/press-room/press-releases/2020/5/gileadannounces-approval-of-veklury-remdesivir-in-japan-for-patie nts-with-severe-covid19. Accessed 24 Jun 2020.

20. Gilead. European Commission grants conditional marketing authorization for Gilead's Veklury ${ }^{\circledR}$ (remdesivir) for the treatment of COVID-19. https://www.gilead.com/news-and-press/ press-room/press-releases/2020/7/european-commission-grantsconditional-marketing-authorization-for-gileads-veklury-remde sivir-for-the-treatment-of-covid19. Accessed 16 Aug 2020.

21. FDA. Veklury (remdesivir): EUA fact sheet for HCP. https://www. fda.gov/media/137566/download. Accessed 7 Dec 2020.

22. Pruijssers A, Lu X, Hughes TM, Gully K, et al. Remdesivir potently inhibits SARS-CoV-2 in human lung cells and chimeric 
SARS-CoV expressing the SARS-CoV-2 RNA polymerase in mice. https://doi.org/10.1101/2020.04.27.064279v1. Accessed 10 Jan 2020.

23. Williamson BN, Feldmann F, Schwarz B, et al. Clinical benefit of remdesivir in rhesus macaques infected with SARSCoV-2. Nature. 2020;585(7824):273-6. https://doi.org/10.1038/ s41586-020-2423-5.

24. de Wit E, Feldmann F, Cronin J, Jordan R, Okumura A, Thomas T, et al. Prophylactic and therapeutic remdesivir (GS-5734) treatment in the rhesus macaque model of MERS-CoV infection. Proc Natl Acad Sci USA. 2020;117:6771-6.

25. Lutz J, Mathias A, German P, Pikora C, Reddy S, Kirby B. Physiologically-based pharmacokinetic modeling of remdesivir and its metabolites to support dose selection for the treatment of pediatric patients with COVID-19. Clin Pharmacol Ther (manuscript in review).

26. Goldman JD, Lye DCB, Hui DS, et al. Remdesivir for 5 or 10 days in patients with severe Covid-19. N Engl J Med. 2020. https://doi. org/10.1056/NEJMoa2015301.

27. Beigel JH, Tomashek KM, Dodd LE, et al. Remdesivir for the treatment of Covid-19: preliminary report. N Engl J Med. 2020. https://doi.org/10.1056/NEJMoa2007764.

28. Sisay M. Available evidence and ongoing clinical trials of remdesivir: could it be a promising therapeutic option for COVID-19? Front Pharmacol. 2020;11:791.

29. Information about Veklury ${ }^{\circledR}$ (remdesivir) from around the world. www.remdesivir.com. Accessed 7 Sep 2020.

30. Study to evaluate the safety, tolerability, pharmacokinetics, and efficacy of remdesivir (GS-5734) in participants from birth to < 18 years of age with coronavirus disease 2019 (COVID-2019) (CARAVAN). https://www.clinicaltrials.gov/ct2/show/NCT04 431453. Accessed 16 Aug 2020.

31. Gilead. Press release: Gilead Sciences statement on phase $2 / 3$ clinical trial of remdesivir in pediatric patients hospitalized with COVID-19. https://www.gilead.com/news-and-press/companystatements/gilead-sciences-statement-on-clinical-trial-of-remde sivir-in-pediatric-patients. Accessed 17 Jul 2020.

32. European Medicines Agency. ICH guideline E14: the clinical evaluation of QT/QTc interval prolongation and proarrhythmic potential for non-antiarrhythmic drugs (R3): questions and answers. 2016. London E14 5EU. https://www.ema.europa.eu/ documents/scientific-guideline/ich-guideline-e14-clinical-evalu ation-qt/qtc-interval-prolongation-proarrhythmic-potential-nonantiarrhythmic-drugs-r3-questions-answers-step_en.pdf.
33. Garnett C, Bonate PL, Dang Q, et al. Scientific white paper on concentration-QTc modeling. J Pharmacokinet Pharmacodyn. 2018;45:383-97.

34. Kirby BJ, Unadkat JD. Impact of ignoring extraction ratio when predicting drug-drug interactions, fraction metabolized, and intestinal first-pass contribution. Drug Metab Dispos. 2010;38:1926-33.

35. Jiang L, Tang K, Levin M, et al. COVID-19 and multisystem inflammatory syndrome in children and adolescents. Lancet Infect Dis. 2020;S1473-3099(20)30651-4 (epub ahead of print).

36. Feldstein LR, Rose EB, Horwitz SM, et al. Multisystem inflammatory syndrome in U.S. children and adolescents. N Engl J Med. 2020. https://doi.org/10.1056/NEJMoa2021680.

37. CDC. Information for healthcare providers about multisystem inflammatory syndrome in children (MIS-C). https://www.cdc. gov/mis-c/hcp/. Accessed 14 Sep 2020.

38. Mohamed MF, Rakhmanina N, Hassan HE. Inclusion of adolescents with adults in phase 3 clinical trials: overview of the current state and a call for action. J Clin Pharmacol. 2020. https://doi.org/ 10.1002/jcph.1591.

39. Zhang H, Liao YS, Gong J, Liu J, Zhang H. Clinical characteristics and risk factors for liver injury in COVID-19 patients in Wuhan. World J Gastroenterol. 2020;26:4694-702.

40. Mogalian E, Brainard DM, Osinusi A, et al. Pharmacokinetics and safety of velpatasvir and sofosbuvir/velpatasvir in participants with hepatic impairment. Clin Pharmacokinet. 2018;57(11):1449-57.

41. Descovy (emtricitabine and tenofovir alafenamide): US prescribing information. Foster City (CA). Revised: Dec 2019.

42. Tamiflu (ostelmavir phosphate): US prescribing information. South San Francisco (CA). Revised: Aug 2019.

43. Ronco C, Reis T, Husain-Syed F. Management of acute kidney injury in patients with COVID-19. Lancet Respir Med. 2020;8:738-42.

44. Mao R, Qiu Y, He JS, Tan JY, Li XH, Liang J, et al. Manifestations and prognosis of gastrointestinal and liver involvement in patients with COVID-19: a systematic review and meta-analysis. Lancet Gastroenterol Hepatol. 2020;5:667-78.

45. Zhang C, Shi L, Wang FS. Liver injury in COVID-19: management and challenges. Lancet Gastroenterol Hepatol. 2020;5(5):428-30.

46. Jothimani D, Venugopal R, Abedin MF, Kaliamoorthy I, Rela M. COVID-19 and the liver. J Hepatol. 2020;73(5):1231-40. 